\title{
A Critical Discussion of The Efficacy of Using Visual Learning Aids From The Internet To Promote Understanding, Illustrated With Examples Explaining The Daniell Voltaic Cell
}

\author{
Ingo Eilks \\ Universität Bremen, Bremen, GERMANY \\ Torsten Witteck \\ Engelbert-Kaempfer-Gymnasium, Lemgo, GERMANY \\ Verena Pietzner \\ Universität Koblenz-Landau, Landau, GERMANY
}

Received 25 February 2008; accepted 19 April 2008

\begin{abstract}
This paper discusses what chemistry students might see while working with animations found on the Internet and how these electronic illustrations can potentially interact to reinforce rather than resolve misconceptions about chemical principles that a student may possess. The Daniell voltaic cell serves as an example to illustrate the ways in which visual aids can be interpreted differently by different people. Some illustrations seem to represent concepts which have repeatedly been discussed on the base of science education research evidence as typical student misconceptions about chemical concepts. These visual aids seem to embody the actual misconceptions of chemical principles rather than explaining the scientifically accepted chemical concepts behind them. This paper discusses whether such computer simulations are potentially helpful for better understanding, or whether they actually increase the risk of strengthening students' incorrect interpretations or false ideas about chemical concepts. Implications for structuring and using animations are discussed.
\end{abstract}

Keywords: Chemistry Education, Multimedia Learning, Animations, Misconceptions

\section{INTRODUCTION}

"WYSIWYG - What you see is what you get" was an innovation in information technology some 15 years

Correspondence to: Ingo Eilks, Professor in Chemistry Education, University of Bremen, Department of Biology and Chemistry, Institute for Science Education (IDN), Leobener Str. NW2, 28334 Bremen, GERMANY

E-mail: ingo.eilks@uni-bremen.de ago. Until this shift towards WYSIWYG-technology occurred, cognitive tools like text editors had not been able to accurately depict edited materials on the computer monitor in their real layout while simultaneously working with and altering them. Frequently, this led to various surprises when printing a hardcopy of the material. Today, it is no longer a problem to display correct fonts, page layouts or picture elements on the screen while simultaneously processing documents and files. Moreover, with the modern tools existing today, there is almost no difficulty in creating 
pictures, simulations, and visual aids in any form and context we like. Modern computer games beautifully demonstrate the current, cutting-edge breakthroughs in developing illustrations and animated programs.

On a certain level animation technology no longer demands highly specialized programmers. Applications like Macromedia Flash have become easy to use and many curriculum planners and teachers are now able to create animated aids using these tools. This has led to a large increase in the number of animated visual aids on the Internet for a variety of science topics. But the question remains whether all of these animated illustrations are truly useful in supporting learning. Does any given illustration from the Internet provide us with what we really want or need to have? Do illustrations support learning processes simply by showing chemical concepts in an electronically animated format?

The question of whether we get what we see or, perhaps more importantly, what students perceive when watching animations, must be asked from a different point of view. This is because focusing on the use of animated illustrations in education is different than discussing computer games played merely for entertainment. We know from constructivist theories of learning (e. g., Bodner, 1986) that visual aids are not captured in learners' heads without being filtered and interpreted using the framework of the viewer's preconceptions. We use illustrations in science education in the hope that they will promote a deeper comprehension and understanding of scientific principles. Such visual aids are used to challenge alternate or incorrect beliefs about scientific principles, and to provoke a shift towards scientifically acceptable concepts. In chemistry, teaching with this goal in mind is especially linked to the understanding of the submicroscopic level of matter, which is invisible to the human eye and therefore largely dependent on human imagination. It is in trying to link what we actually observe to what happens at the submicroscopic level that causes the main difficulties in learning chemistry (Johnstone, 1991).

We will discuss differences in what learners can conclude by viewing illustrations found in the Internet by using two illustrations of the Daniell cell as examples. A look at both the potential perspectives of teachers and those of learners viewing the same images may help to sensitize us more deeply to the possible interpretations of computer-animated illustrations.

\section{Learning by visualisation}

Today learning as a whole and so learning with visualisations is generally referred to a constructivist understanding of learning as described, e. g., by Bodner (1986). The central message is that students get information, e. g. via a computer screen, and will construct from this information together with the knowledge they have new ideas and concepts. In his article on contructivist learning, Storck (1995) points out three essentials:

Concepts, ideas and knowledge that the students bring
with them into the classroom have to be taken into account
when evaluating, planning and structuring learning
processes.
Provoking cognitive conflicts and their solutions is of high
potential value for facilitating a change in student
preconceptions into valid scientific concepts.
It is not necessary that alternative ideas about chemical
principles will be replaced by scientific "truths" in all cases.
There are situations where it seems to the student do be of
more value to retain more naive ideas or beliefs about
scientific processes or theories. One example may illustrate
this. In our everyday life, we regularly speak about the
consumption of energy. It is clear that we bave to support
an electronic device by electricity, or a car by gasoline as a
source of energy. The correct idea of a change from one form
of energy into another under recognition of the principle of
Conservation of Energy is not necessary here because we
are thinking within this context exclusively on those forms
of energy that can be used in our interest in that moment,
and maybe on the costs for supplying us with "usable"
energy.

Constructivist learning has been one of the leading forces for intensive empirical research into students' alternate beliefs about chemistry and also into their learning problems. Evidence has been gained in many different fields (e. g., Garnett, Garnett and Hackling, 1995), for example, electrochemistry-respective reviews were given by Garnett and Treagust (1992 a) and de Jong and Treagust (2002). Many of these studies focused on the details of understanding electrochemical cells. For a deeper understanding of this field, additional relevant information also can be obtained from more basic research on the particulate nature of matter or on the theories for understanding electricity (e. g., de Jong and Treagust, 2002).

Constructivist learning seeks to explicitly pinpoint alternate ideas about chemistry and to create learning environments where these alternate beliefs can be discussed and replaced with less naïve and scientific reliable concepts. This can be achieved by provoking a cognitive conflict and then using this conflict to promote a conceptual change (Posner, Strike, Hewson and Gertzog, 1982), e. g. where the naïve ideas can be falsified by the use of experiments. An example may illustrate this. Teachers frequently report that ions within an electrochemical cell are thought by many students to come "out of" the electrode. They then disappear after being uncharged at the electrode. In the students' minds this is not always connected with a gain or loss in the mass of the two oppositely-charged 
electrodes. The chemical principles of Conservation of Mass and Conservation of Atoms are not correctly applied. Students often think that the electrodes in a voltaic cell always remain unchanged during the whole process, just like the external electric circuit does. We will return to this misconception later in the discussion of different visual aids. This misconception can easily be disproved scientifically if, for example, a Daniell cell is set up and connected to an electronic device for a few hours. Both electrodes can be weighed and the loss in mass of the zinc anode and the increase in mass of the copper cathode can be measured and compared with the starting values. This experiment can be used to provoke a cognitive conflict in those students who neglect the change in mass occurring in the electrodes. Additionally, such experiments show the hands-on, experimental nature of science. A hypothesis is proposed and then proven or disproven through experimentation, the same path that Lavoisier, Boyle, or Berzelius were forced to follow in their quest for knowledge of the physical world.

Unfortunately, this scenario is limited to the phenomenological level. In most examples focusing on concepts and alternate ideas of the submicroscopic world, a similar approach is not available and this is why chemistry is so difficult to learn (Johnstone, 1991). In chemistry, we often use models to help us better understand phenomena at the submicroscopic level. With improvements in computer technology, it is now common to use computer-generated animations and simulations of the submicroscopic world. Such computer-animated illustrations provide considerable advantages over static images because they allow us to visually demonstrate the dynamic nature of the submicroscopic world.

According to Mayer (2003), students can learn more profoundly from a multimedia explanation presented in both words and pictures than in words alone ("the multimedia effect"). This effect is explained by the dual coding theory of Pavio (1986) that states that visual and verbal information in the brain are processed differently and along distinct channels while the learner creates separate representations in each channel. These different codes can interact and promote succesful learning. But, this promising process is not self evident. Schnotz and Bannert (2003) discuss the fact that pictures in multimedia learning processes are not necessarily of benefit to learning in every case. Pictures can only be understood by semantic processes. Also, pictorial information is always related to the preknowledge of the learner. Learning effectiveness is highly dependent on students' preconceptions. Therefore, if effective learning should take place illustrations and visual aids need to be structured to take account of the learner's pre-knowledge of a given topic. This means:
If the learner's preconceptions are scientifically reliable, illustrations should confirm and foster them.

If the learner's preconceptions of a topic are scientifically unreliable, illustrations should induce a cognitive conflict which leads to overcoming the formerly-held ideas.

In both cases it is necessary to use illustrations that are scientifically reliable and that do not demonstrate or call upon incorrect or conflicting explanations. Generally, we would think that this could always be taken for granted, but even static illustrations in school textbooks do not always meet these criteria (e. g., Eilks, 2003).

\section{The Daniell voltaic cell as example}

The Daniell cell is one of the most familiar and easyto-use voltaic cells and is therefore the chosen example for voltaic cells in many science curricula. Nevertheless, the following discussion is just an exemplary case. Similar examples could be found for a range of other science topics.

Because the Daniell cell is an often-discussed topic in chemical education, many visual aids are available on the Internet. Appendix 1 lists a number of such resources for the Daniell cell from different countries. One of the examples from a German website (Figure 1) for secondary and tertiary education will be used as our first example to show the problems in "seeing" animations which do not "really" animate the science concept which is commonly accepted within the scientific community. Some of the other animations in Appendix 1 are quite better models to explain Daniell's voltaic cell in terms of our commonly accepted scientific view, while others are questionable in a similar way.

What do we see when we look at the five diagrams in figure 1? The figure illustrates steps in the animation, and the formation of zinc ions from the zinc electrode can be recognized. The external electrical circuit is completed by a salt bridge. Zinc ions are solvated by the aqueous solution around the anode. Connected to this process, two electrons are set free. The external electrical circuit conducts these electrons toward the copper electrode. The electrons become available for reducing metal ions at the copper electrode. Copper ions in the solution move toward the copper cathode and accept the electrons. Copper atoms are formed and deposited on the copper electrode. Overall, we see a flow of electric current, which would be able to power a small engine.

But is this really what we see? Most of the things described above cannot, in fact, be seen within the animation. Most of the steps involved are interpretations stemming from the pre-knowledge we possess: They represent rather our teacher's expert knowledge of voltaic cells. 

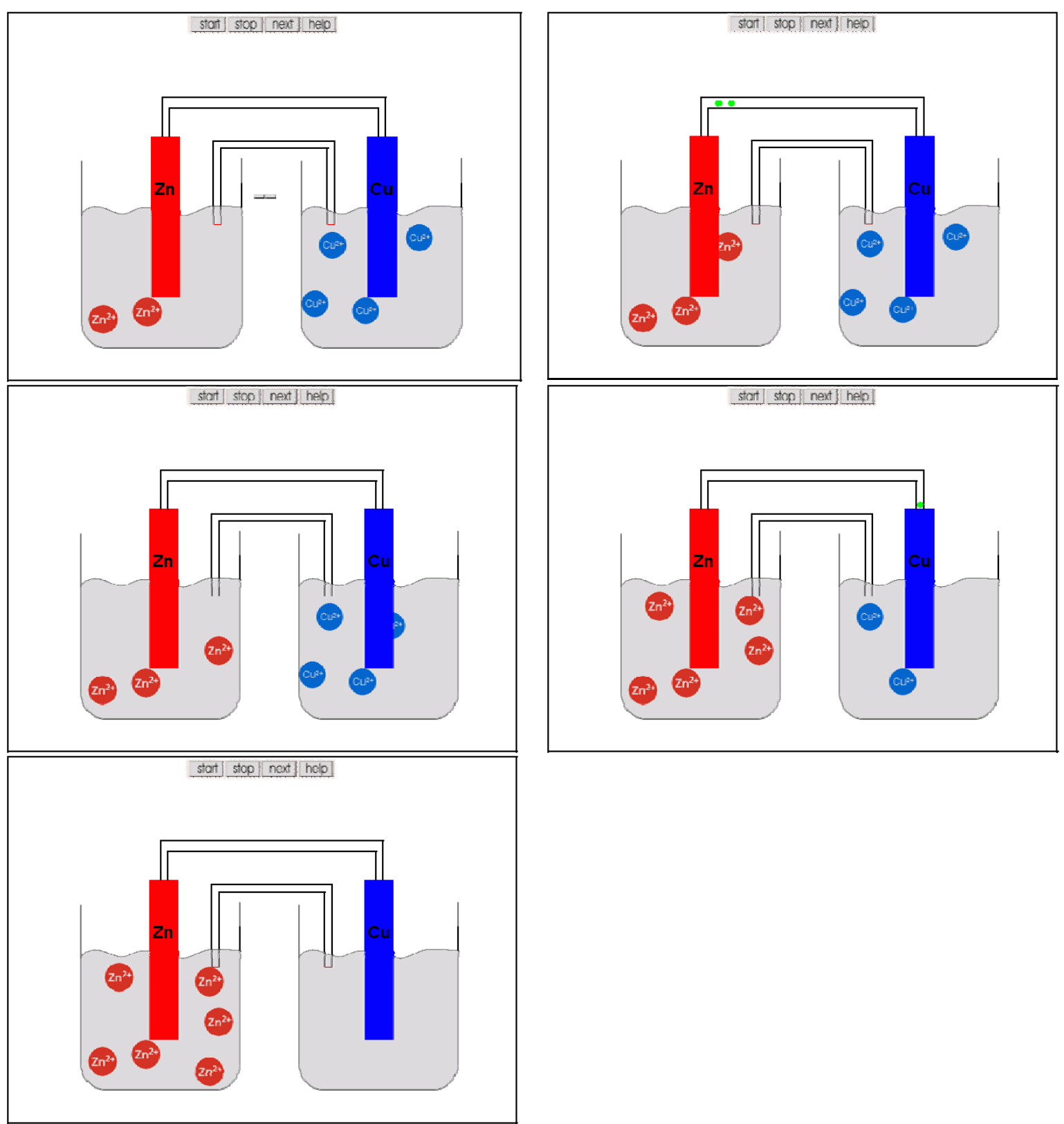

Figure 1: An animation on the Daniell cell from the internet (ChemgaPedia, 2008)

What then do we really see? What we see is a zinc electrode. This electrode is represented as a continuum: it does not consist of atoms. If we take into consideration the fact that zinc atoms are larger than the corresponding zinc ions, it is impossible to believe that the zinc electrode consists of zinc atoms. The electrode is thinner than any of the zinc atoms could possibly be. Starting at the zinc electrode, zinc ions move into the solution. The ions either come out of the electrode or from behind it. The ions move into a continuous "grey zone", which is not involved in the whole process. During the entire reaction there are no changes in the zinc electrode's mass or size. It is not reduced (see above). Accompanying the appearance of the zinc ions, 
Table 1. Selected results from empirical research about scientifically unreliable concepts from students, with relevance for understanding electrochemical cells

- The particulate nature of matter often is misinterpreted as an understanding of particles within a continuum (Novick and Nussbaum, 1978). Sometimes an understanding of the particulate nature of matter within a system is limited to single substances. These are those substances which are in the focus of the discussion (Ahtee and Varjola, 1998). These kinds of mixed interpretations sometimes are kept during the whole schooling time (Nakleh, 1992).

- Macroscopic changes are sometimes referred to as similar changes in the particles (Lee, Eichinger, Anderson, Berkheimer and Blakeslee, 1993). This can be true even for mass changes. If matter is no longer visible it seems to disappear along with its particles (Stavy, 1990). It is not only important to keep the principle of mass conservation in mind, but also to retain the principle of atom conservation (Gomez, Pozo and Sanz, 1995).

- Current flow often is over-generalized as a flow of electrons. This is a reliable idea for portraying conductivity in metals. But sometimes an understanding of electrolytic conductivity as a flow of free electrons through the electrolyte has been observed. The concept of the movement of ions is not applied (Grosslight, Unger, Jay and Smith, 1991; Garnett and Treagust, 1992b; Ogude and Bradley, 1994, 1996).

- Current flow is not necessarily connected to the concept of a circuit. There are misinterpretations in understanding electric current as something flowing from the source to the device (de Posada, 1997). The necessity of a salt bridge therefore is not understood. The external and internal electric circuits are not seen as one entity (Burger, 2000).

- Students sometimes adhere to a concept where electrolytes do not contain ions, but instead salts. Ions are formed at the moment voltage is put across the solution or an electrolytic process started (Ogude and Bradley, 1994, 1996; Butts and Smith, 1987)

Table 2. Some ideas from empirical research and taken into account, some compromises made in figure 2

\begin{tabular}{ll}
\hline Considered ideas & Compromises \\
\hline $\begin{array}{l}\text { Electrodes are composed of atoms of zinc or copper, } \\
\text { respectively. During the reaction, zinc atoms are }\end{array}$ & $\begin{array}{l}\text { The particles of the solvent are not shown. The level of the } \\
\text { solution is sketched, but a grey or colourful sketch of a }\end{array}$ \\
$\begin{array}{ll}\text { changed into ions. The zinc ions are dissolved. } \\
\text { Solvated copper ions are changed into copper atoms }\end{array}$ & $\begin{array}{l}\text { continuum is not shown. Additional information is } \\
\text { and form new copper at the copper electrode. }\end{array}$ \\
showing all particles within both half-cells.
\end{tabular}

No particles seem to spontaneously appear from

nothing or disappear into nothing. The principles of

conservation of mass and the conservation of atoms

are considered.

Chemical change in particles leads to change in the

electrodes' mass and structure. The zinc electrode

becomes smaller, the copper electrode becomes bigger.

There is no visualisation of a flow of electric current

only from one half-cell to another.

Conductivity of the external electric circuit and the salt bridge is not explicitly shown in the animation. Additional information is available as a pop-up window, where both the processes of conductivity in metals and in electrolytes are explained.

two electrons are released. These same two electrons move through an envisioned "electron channel" towards the copper electrode, which is a questionable construct of electric conductivity in metals. Also the copper electrode is represented as an unaffected continuum. A copper ion from the solution moves towards the charged electrode. Together with the disappearance of the two zinc-generated electrons, a copper atom is formed and disappears into or behind the copper electrode. Similarly this second electrode does not change throughout the process. The zinc electrode does not appear to become smaller, nor does the copper electrode appear to get larger. It is obvious that both electrodes have no more in common with the redox reaction than the external wire circuit or the salt bridge. The salt bridge exists, but it is not involved in the dynamics of the process. Particles or charges are not transported via the salt bridge, although the salt bridge seems to be the same as the external circuit. In interpreting the picture of the external circuit ("the electron channel") only electrons can be transported. The salt bridge looks the same, since ions seem to be too large for passing the salt bridge. Even the transport 
of charges in electrolytes as a free-flow of electrons is an often-documented misconception among students. ...

But why then do we "see" what we believe we see? Our "expert knowledge" leads us to perceive what we wanted to see: An animated illustration of the Daniell cell. Within seconds we reconstruct our knowledge using the impulse of the animated picture to obtain the correct view. The observed content is no longer of interest to us. Unfortunately, we can't expect the same for our students.

\section{Students' alternative ideas revisited}

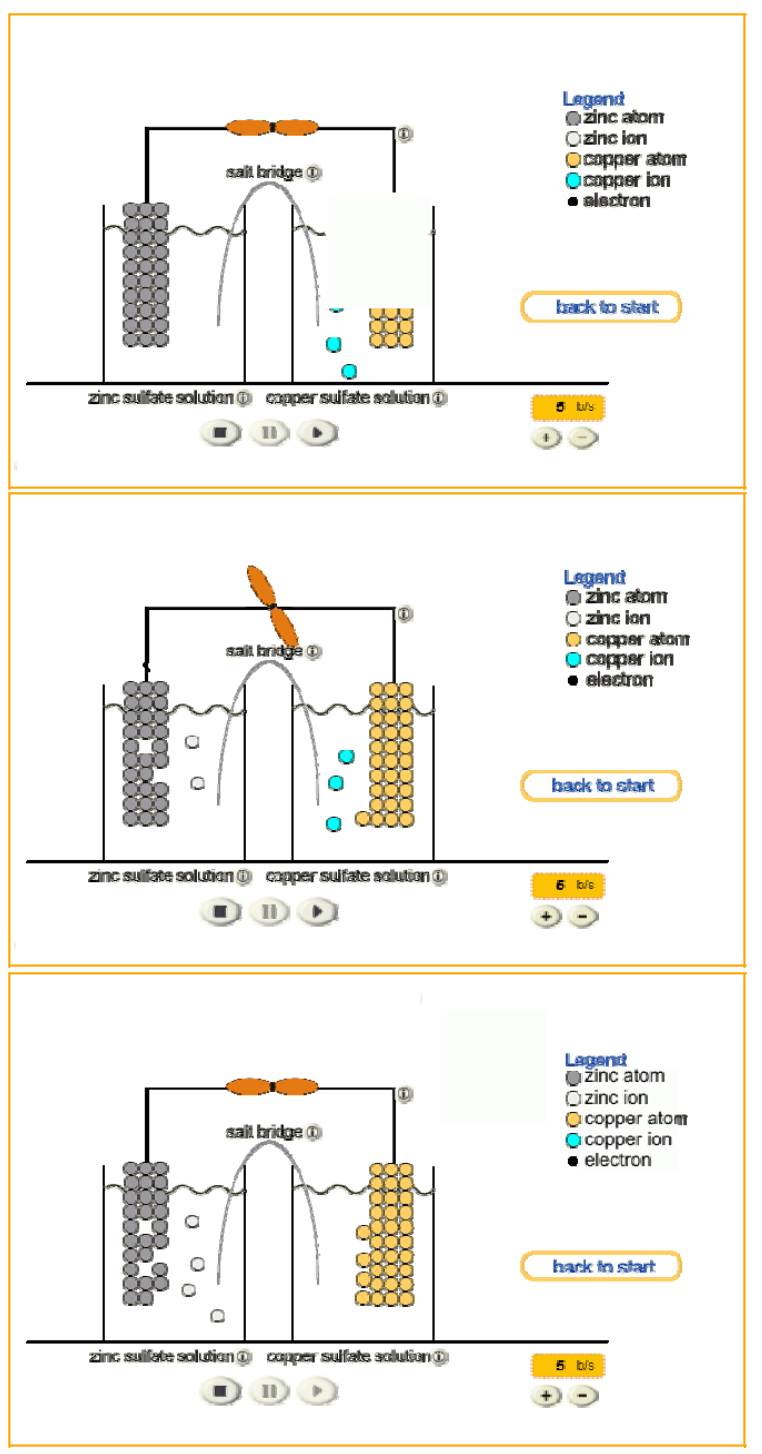

may no longer be any misunderstandings, but can we be confident in this belief? If we view model-based thinking as a serious task in scientific learning, we need to recognise that the above-mentioned animations are not the models but merely illustrations of the scientific model; it is just a teaching model Justi and Gilbert, 2002b). The scientific models, or scientific theories, as we may call them, are the ideas behind: The scientific models of particles, atoms and atomic structures, or the model of electron-transfer. Teachers will recognize quite quickly where illustrations and scientifically accepted models depart from one another. This, however, cannot be expected from students. In most cases, students do

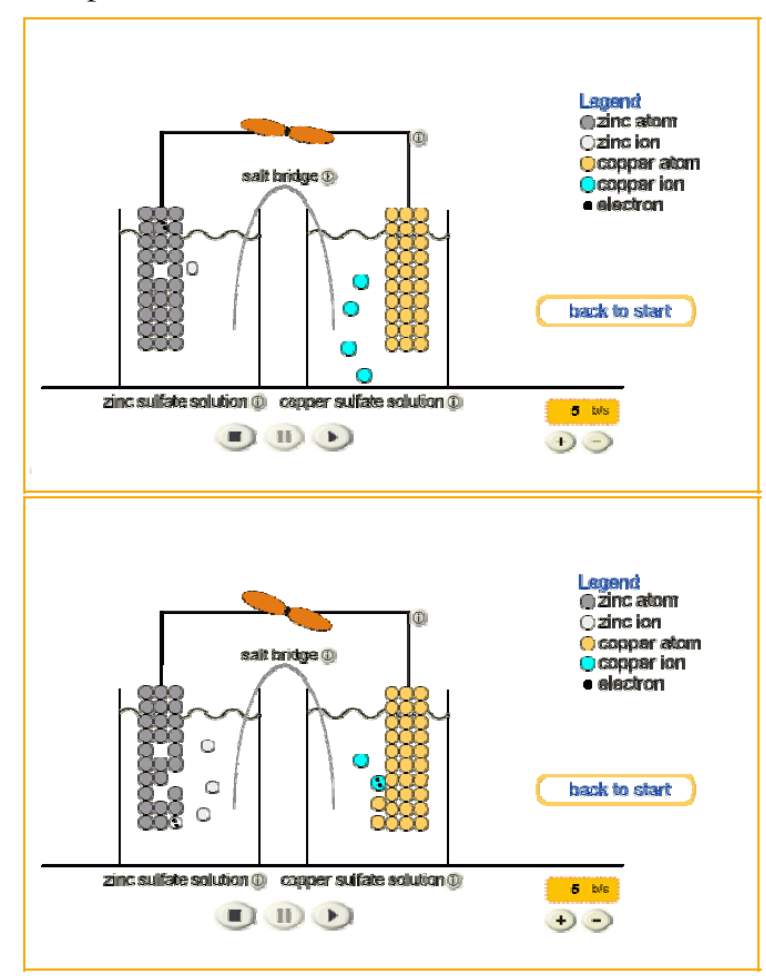

Figure 2. Draft of an animation on the Daniell cell (Pietzner, Eilks, \& Witteck, 2008). Originally produced in German, but an English version is also available.

You may think that our interpretation of the abovediscussed animation is much exaggerated. This may be true. One may think this is only a model. Models always use shortcuts and simplifications to represent its target (van Driel and Verloop, 1999). If a model is sufficiently discussed and reflected upon in the classroom, there not have a sufficiently-developed understanding of scientific models and modelling (Grosslight, Unger, Jay and Smith, 1991), unfortunately this may also be true for some teachers (e.g. van Driel and Verloop, 1999; Harrison, 2000; Justi and Gilbert, 2002a and b). In the 
same vein, students lack a developed understanding of the processes occurring in the submicroscopic world.

Empirical research has revealed that there are many alternate beliefs that students hold about matter and chemical change. These results consequently suggest many points to keep in mind when viewing animations as a potential, helpful tool for learning. Table 1 gives some selected results, which may be important for understanding the visual representations of the Daniell cell discussed above. However, it is very difficult to create a visual aid both showing the processes within the Daniell cell and also recognizing all the consequences of students' alternate beliefs. Simplifications appear to be necessary to reach some kind of clarity for the learner. But which kind of simplification is acceptable, and which will only serve to nurture students' alternate beliefs? Of course, we don't have a definitive answer. But to start a discussion, figure 2 shows a draft visual aid. Table 2 discusses some results from empirical research which had been taken into consideration, but shows also some compromises.

\section{IMPLICATIONS}

Using our criteria, even the second visual aid is far from perfect; even here compromises were necessary. The purpose of this paper is not to explain how a perfect simulation of the Daniell cell should appear. Rather it discusses how difficult it is to create a potentially-helpful visual aid for students to learn chemistry. Our example also shows that it is often easier to make progress by considering the results from empirical research. Another lesson we can derive from the above discussion is that it can be very risky to use information technology and visual aids which have not been thoroughly considered and tested to identify any potential problematic interpretations from the student's point of view. Animations too often seem to have a greater potential to foster misconceptions than to promote scientific understanding, especially if they are constructed without sufficient reflection on the learners' perspective and pre-knowledge.

Appendix 1 offers different examples for animations of Daniell's voltaic cell in different languages. If we consider these examples from a "naïve" point-of-view, we encounter many interesting interpretations. This is the same viewpoint used by students who know little about the chemical principles behind the visual aids, and who do not have a developed understanding of model use. Such an activity to write down a naïve interpretation of pictures and animations and to compare them to research results proved to be a fruitful exercise in teacher training seminars.

It is easy to be distracted into making all our images colorful, attractive and animated. This seems to be the motivation of many Internet sources. But, it is surely more important that the animations should not be misleading.

\section{Acknowledgement}

We thank Bill Byers for his critical review on the final manuscript and his helpful remarks.

\section{REFERENCES}

Allchin, D. (1998). Values in science and science education. In B.J. Fraser \& K.G. Tobin (Eds.), International handbook of science education (pp. 1083-1092). Dordrecht: Kluwer.

Ahtee, M., \& Varjola, I., (1998). Students' understanding of chemical reaction. International Journal of Science Education, 20, 305-316.

Bodner, G. M. (1986). Constructivism - A theory of knowledge. Journal of Chemical Education, 63, 873.

Burger, N. (2000). Vorstellungen von Schülern über Elektrochemie eine Interviewstudie [Students' conceptions about electro-chemistry - an interview study]. Dissertation, University of Dortmund.

Butts, B., \& Smith, R. (1987). What do student perceive as difficult in H.S.C. chemistry?. Australian Science Teachers' Journal, 32, 45-51.

ChemgaPedia (n.d.). Retrieved June 20, 2008, from http://www.chemgapedia.de/vsengine/vlu/vsc/de/ch /13/vlu/echemie/galvanische_elemente/batterie.vlu/P age/vsc/de/ch/13/pc/echemie/galvanische_elemente/ daniellapplet.vscml.html

de Jong, O., \& Treagust, D. F. (2002). The teaching and learning of electrochemistry. In J. K. Gilbert, O. de Jong, R. Justi, D. F. Treagust \& J. H. van Driel (Eds.), Chemical Education: Towards research-based practice (pp. 317338). Dordrecht: Kluwer.

de Posada, J. M., (1997). Conceptions of high school students concerning the internal structure of metals and their electric conduction: Structure and evolution. Science Education, 81, 445-367.

Eilks, I. (2003). Students' understanding of the particulate nature of matter and some misleading illustrations from textbooks. Chemistry in Action, No. 69, 35-40.

Garnett, P. J., Garnett P. J., \& Hackling, M. W. (1995). Students' alternative conceptions in chemistry: A review of research and implications for teaching and learning. Studies in Science Education, 25, 69-95.

Garnett, P. J., \& Treagust, D. F. (1992a). Conceptual difficulties by senior high school students of electrochemistry: Electric circuits and oxidationreduction equations. Journal of Research in Science Teaching, 29, 121-142.

Garnett, P. J., \& Treagust, D. F. (1992b). Conceptual difficulties experienced by senior high school students of electrochemistry: Electrochemical (galvanic) and electrolytic cells. Journal of Research in Science Teaching, 29, 1079-1099.

Gomez, M.-A., Pozo J.-I., \& Sanz, A., (1995). Students‘ Ideas on conservation of matter: Effects of expertise and context variables. Science Education, 79, 77-93.

Grosslight, L., Unger, C., Jay E., \& Smith, C. (1991). Understanding models and their use in science: 
conceptions of middle and high school students and experts. Journal of Research in Science Teaching, 28, 799-822.

Harrison A. G., (2000), How do teachers and textbook writers model scientific ideas for students?. Paper presented at the NARST annual meeting, New Orleans.

Harrison, A. G., \& Treagust, D. F. (2002). The particulate nature of matter: Challenges in understanding the submicroscopic world. In J. K. Gilbert, O. de Jong, R. Justi, D. F. Treagust \& J. H. van Driel (Eds.), Chemical education: Towards research based practice (pp.189-212). Dordrecht: Kluwer.

Johnstone, A. H. (1991). Why is science difficult to learn? Things are seldom what they seem. Journal of Computer Assisted Learning, 7, 75-83.

Justi, R. S., \& Gilbert, J. K. (2002a). Science teachers' knowledge about and attitudes towards the use of models and modelling in learning science. International Journal of Science Education. 24, 1273-1292.

Justi R. S., Gilbert, J. K. (2002b). Models and modelling in chemistry education. In J. K. Gilbert, O. de Jong, R. Justi, D. F. Treagust \& J. H. van Driel (Eds.), Chemical Education: Towards research-based practice (pp. 47-68). Dordrecht: Kluwer.

Lee, O., Eichinger, D. C., Anderson, C. W., Berkheimer, G. D., \& Blakeslee, T. D. (1993). Changing middle school students' conceptions of matter and molecules. Journal of Research in Science Teaching, 30, 249-270.

Mayer, R. E. (2003). The promise of multimedia learning using the same instructional design methods across different media. Learning and Instruction, 13, 125-140.

Nakhleh, M. B. (1992), Why some students don't learn chemistry. Journal of Chemical Education, 69, 191-196.

Novick, S., \& Nussbaum, J. (1978). Junior high school pupils' understanding of the particulate nature of matter: an interview study. Science Education, 62, 273-281.

Ogude, A. N., \& Bradley, J. D. (1994). Ionic conduction and electrical neutrality in operating electrochemical cells. Journal of Chemical Education, 71, 29-34.

Ogude, A. N., \& Bradley, J. D. (1996). Electrode processes and aspects relating to cell EMF, current and cell components in EC Cells. Journal of Chemical Education, 73, 1145-1149.

Pavio, A. (1986), Mental respresentations: A dual coding approach. Oxford: Oxford University Press.

Pietzner, V., Eilks, I. \& Witteck, T (2008). Retrieved June 20, 2008, from http://www.chemieunterrichtinteraktiv.de/en/animations/electrochemistry/daniell_c ell/daniell_en.html

Posner, G. J., Strike, K. A., Hewson, P. W., \& Gertzog, W. A. (1982). Accommodation of a scientific conception: Toward a theory of conceptual change. Science Education, 66, 211-227.

Schnotz, W., \& Bannert, M. (2003). Construction and interference in learning from multiple respresentations. Learning and Instruction, 13, 117-123.

Stavy, R. (1990). Children's conception of changes in the state of matter: from liquid (or solid) to gas. Journal of Research in Science Teaching, 30, 247-266.

Stork, H. (1995). Was bedeuten die aktuellen Forderungen „Schülervorstellungen berücksichtigen, ,konstruktivistisch'lehren!,, für den Chemieunterricht in der Sekundarstufe I? [What does the actual plea
,Considering Students ideas, teach constructivitictly! mean for lower secondary chemistry lesson?]. Zeitschrift für Didaktik der Naturwissenschaften, 1, 15-28.

van Driel, J. H., Verloop, N. (1999). Teachers' knowledge of models and modelling in science. International Journal of Science Education, 21, 1141-1153.

\section{$\diamond \diamond \diamond$}

\section{Appendix 1. Animations on the Daniell cell from the internet; last access (20 June 2008)}

1. www.chemgapedia.de/vsengine/vlu/vsc/de/ch/ 13/vlu/echemie/galvanische_elemente/batterie.v $\mathrm{lu} / \mathrm{Page} / \mathrm{vsc} / \mathrm{de} / \mathrm{ch} / 13 / \mathrm{pc} /$ echemie/galvanische _elemente/daniellapplet.vscml.html

2. www.ltam.lu/chimie/DaniellElementCD.html

3. www.mhhe.com/physsci/chemistry/essentialche mistry/flash/galvan5.swf

4. www.chem.iastate.edu/group/Greenbowe/sectio ns/projectfolder/flashfiles/electroChem/volticC ell.html

5. www.chem.iastate.edu/group/Greenbowe/sectio ns/projectfolder/flashfiles/electroChem/voltaic Cell20.html

6. www.chem.iastate.edu/group/Greenbowe/sectio $\mathrm{ns} /$ projectfolder/animations/CuZncell.html

7. www.edunet.tn/ressources/resdisc/physique/mo nastir/pile/epd.htm

8. http://www.chemieinteraktiv.net/html_flash/redox.swf

9. www.chempage.de $\rightarrow$ "Theorie“ $\rightarrow$ „Galvanische Zelle“ 